carity and the peritoneum with great care, and closed the wound with a glass tube reaching to the bottom of the cyst. The patient made an easy and uninterrupted recovery, and went home on Nov. 14th last. The interest of the case lies in the circumstance that, as one of interstitial tubal pregnancy, it is of great rarity and it constitutes the first instance in which surgical assistance has anticipated the rupture and the patient's life has been saved. I have said in my" Lectures on Ectopic Pregnancy" that I thought itvery unlikely that anyone would ever have such an opportunity, and I do not think that $I$ should have been so fortunate in this instance but for the circumstance that the foetus had died and the process of suppuration was making enough constitutional disturbance to demand interference. The usual fate of the primary zupture was thus avoided, a rapture by the slower process of suppuration was substituted, and thus time was saved by the warning given.

The Grescent, Birmingham.

\section{ERYTHEMA NODOSUM IN A MALE ADULT.}

\section{BY J. G. M'NaUght, M.B., C.M. Glasg.,} SURGEON-LIEUTENANT, ARMY MEDICAL SERVICE.

A SERGEANT aged twenty-six years was admitted to hospital on Dec. 2nd, 1893, suffering from chronic inflammation of the inguinal glands, not venereal in origin. On Dec. 9th he complained of pain in the elbow-joints and knee-joints. Next day he still complained of pain. None of the joints complained of were swollen and the pain was not very acute. On examination an eruption was noticed on his legs, extending from just above the knees to the ankles. It consisted of raised patches of a rose-pink colour; on the front of the legs the patches were oval in shape and from $1 \frac{1}{2} \mathrm{in}$. to 2 in. in ength, the long diameter being parallel to the tibia. In the neighbourhood of the knees the eruption consisted of smaller, rounded patches. He stated that the eruption was painful and it was distinctly tender to the touch. The larger patches felt distinctly nodular. The patient had never suffered from rheumatism, but his mother is subject to it. He stated that he had never had syphilis, and no evidences of his having suffered from that disease were found on careful examination. On the evening of the day on which the eruption appeared his temperature was $102 \cdot 2^{\circ} \mathrm{F}$. His temperatore remained elevated for a week, the following being the readings on successive evenings-102 $101.8^{\circ}, 102^{\circ}, 992^{\circ}$, $39.2^{\circ}$. The eraption became darker in colour and gradually faded, leaving behind it patches of livid discolouration rexactly like that resulting from a bruise. He remained free from fever and pain from Dec. 16th to the 22nd, when he again complained of pain in the elbow-, finger-, knee-, and ankle-joints. The left ankle-joint was distinctly swollen, but theotheraffected joints were unaltered in shape. Together with the articular pains an eruption exactly similar to that already described reappeared, but this time its distribution was more extensive, reaching from the ankles to the hips. The pains in the joints were somewhat more severe on the second occasion, and the feverishness more pronounced. The evening temperatures from Dec. $22 n d$ were as follow : $101.8^{\circ}, 102^{\circ}, 102^{\circ}$ $102^{\circ}, 100 \cdot 6^{\circ}, 100 \cdot 2^{\circ}, 99.8^{\circ}, 98 \cdot 6^{\circ}$. The eruption ran a similar course to that of the one first noticed. As Dr. Hilton Fagge states in his work on the "Practice of Medicine" I that erythema noclosum when it affects males almost always appears in boys about the age of puberty, I thought this case of its occurrence in an adult male worthy of record.

Curragh Camp.

\section{DIPHTHERTA AND ITS CAUSATION.}

By H. Graxt Sutroy, MI.D. St. AxD., M.R.C.S. Eng., MEDICAL OYFICER OF HEALTH FOR THE SITTINGBOURNE AND MLTON RERAL DISTRICTS.

As so little, comparatively, is known as to the origin of diphtberia, and the results of careful observers (though accepted for a time) are often in the end discarded as not altogether satisfactory, I can quite understand that the riews I entertain as to one cause of this disease will be received by some with reserve; still, any facts that tend to throw light upon its origin will, I believe, be acceptable. In large quantities of refuse from the London dustbins are brought down by barges and shot upon a quay, very few houses being contiguous. Immense heaps, some $15 \mathrm{ft}$. high and many yards long, are thus deposited and after some months are sifted for the sake of the contained ashes, which are used for the purposes of brick-making, which is a large industry in this neighbourhood; the residue, consisting of decomposing animal and vegetable matter, rags, woollen materials, old chair seats, feather beds, and all kinds of rabbish and filth, is then burnt, the stench being abominable. These masses of refuse lie smouldering for weeks, and though the gases are volatilised their poisonous properties are not destroyed, and so these noxious fumes are carried in the direction favoured by the wind, one of which would probably be over the village where diphtheria did actually occur.

On March 25th, 1892, in a cottage at a higher elevation than the rubbish in question, and situated some 150 yards distant, two children were simultaneously taken ill with diphtheria. On April 5th a child living in an adjoining cottage developed the first signs of the same malady and may have been infected by its sick neighbours or by the rubbish emanations. On the 6th a young man living some 500 yards away was also sent to the isolation hospital suffering from diphtheria; he, however, had had no connexion whatever with the first two infected dwellings or their inmates. On the 8th another case appeared near the house first infected, which, like the second, may have originated from direct infection from another sick person or from the contaminated atmosphere. The village of Upchurch stands high; the cottages are well built, scattered, and very wholesome; the drainage is in good order, and there is a large air space around the dwellings. After due inquiry as to the origin of the first and subsequent cases, and on finding no other reason for the outbreak, I came to the conclusion that these cases (at any rate the first and third) of diphtheria originated in the deleterious emanations generated in such immense volumes and were "air-borne," especially as there was an utter absence of proof, or even suspicion, of direct personal contagion, and no evidence pointing to schools as the cause. I am fully of opinion that this disease originates with insanitary conditions, especially foul nuisances. I may add that each case as notified was removed to the isolation hospital, otherwise it is most probable that many others would have been attacked.

Sittingbourne, Kent.

\section{A CASE OF ANILINE POISONING.}

By Fred. J. Smith, M.D. Oxon., F.R.C.S. Eng., ASSISTANT PHYSICIAN TO, AND LECTURER ON FORENSIC MEDICINE AND TOXICOLOGY AT, THE LONDON HOSPITAL.

THE following notes of the symptoms in a case of aniline poisoning were supplied by Mr. T. K. Bowkett:- "On Wednesday, Dec. 13th, 1893, I was called to see a woman forty-two years of age, of alcoholic tendencies. The history, as ascertained afterwards, was that at 1.40 P.M. she had swallowed about three ounces of marking ink, the greater part of which consisted of aniline. No immediate symptoms appeared, but after a little while a friend noticed that she looked ill and helped her up to bed, and then the patient rapidly became unconscious. I saw her with Mr. A. Corner at 3 P.M., when her condition was as follows. The lips were of a dark purple, the general surface of the skin was deadly white, with a slight bluish tinge; the conjurctival reflex was present, the pupils were small, with very sluggish and slight reaction to light the breathing was slightly stertorous and the pulse was full and slow, 60 per minute; there was feeble twitching of the muscles of the fingers of both hands. The stomach was thoroughly well washed out with several quarts of warm water, ether was injected subcutaneously, and the inhalation of oxygen also tried; the condition improved a little, but the patient never recovered consciousness and died almost exactly twelve hours after the poison was taken." Mr. Bowkett was kind enough to ask me to be present at the necropsy, which was postponed for my convenience till thirtytwo hours after death. Rigor mortis was still present; there was no noticeable peculiarity about the colour of the corpse, 